\title{
Structural and Spectroscopical Studies for a Complex Macromolecule (hGH)
}

\author{
Perry Habib S. Ali ${ }^{1}$ Nazk Mohammed Aziz ${ }^{2}$ \\ ${ }^{l}$ Assis.Prof. Biochemistry, College of Science for women, University of Baghdad. \\ ${ }^{2}$ lecturer inorganic chemistry. University of Sulaimani, faculty of science and science education, school of \\ science, dept. of chemistry
}

\begin{abstract}
This paper tries to find the effect of the different environmental changes of ( $\mathrm{pH}$, ionic strength, and temperature) on their tertiary structure of hGH by using UV sepctoscopy. We found that the hormone affected by chemical reagents change its conformation and folding. The present study is an attempt to discover what could happen to GH molecule when the biochemistry of body is changed. The results reveal that tryptophyl residues are inside the hormone, whereas tyrosyl residues are on the surface.
\end{abstract}

Key words: $h G H, U V$ spectroscopy, Urea, divalent cation, halides

\section{Introduction}

Complex molecules like protein that do most of the work in the cell have both structural and regulatory functions which are required for body's tissues and organs. Each protein in the cell contain up to 20 different amino acid that bond to each another to make a define and stable three dimensional structure. Many environmental changes could lead to unstable tertiary structure and finally loss of protein function.

Growth hormone (GH) is a single polypeptide hormone with 191 amino acid with a molecular mass of about $22 \mathrm{KDa}^{(1,2)}$. In this research we will try to study the effect of the environmental changes( $\mathrm{pH}$, ionic strength, and temperature ) on the tertiary structure of the GH by using UV. Spectroscopy.

Material:

\section{Material and Methods}

All chemicals used in this study were of analytical grade unless mentioned other wise, and were obtained from companies mentioned below:-hGH : from immunoradiometric assay kit-Immunotech. (France), $\mathrm{HCl}, \mathrm{CaCl}_{2} \cdot 2 \mathrm{H}_{2} \mathrm{O}, \mathrm{MgCl}_{2} \cdot 6 \mathrm{H}_{2} \mathrm{O}, \mathrm{ZnSO}_{4} \cdot 7 \mathrm{H}_{2} \mathrm{O}, \mathrm{CuSO}_{4} \cdot 5 \mathrm{H}_{2} \mathrm{O}$, Urea, , Acetone, Acetic acid, B.D.H (UK).TrisHCl, Glycine, $\mathrm{NaOH}, \mathrm{KCl}, \mathrm{Na}_{2} \mathrm{HPO}_{4}, \mathrm{NaH}_{2} \mathrm{PO}_{4}, \mathrm{NaF}, \mathrm{NaCl}, \mathrm{NaBr}$, NaI- Redial, Hnoffa (Germany).

\section{Methods:}

1. hGH spectrum: hGH molecule was scanned in the range( $200-350 \mathrm{~nm})$ to determine the $\lambda$ max of the macromolecule. In brief, $(50 \mu \mathrm{l})$ of hGH $(10 \mathrm{mIU} / \mathrm{L})$ were completed to $(3 \mathrm{ml})$ with phosphate buffer of $\mathrm{pH}(7.4)$. UV.-Visible Rco. And spectrophotometer, UV-160.

\section{Factors Affecting the Absorption of hGH: \\ 1 - PH Effect:}

$\mathrm{pH}$ effect on hGH was examined by using different buffer with different $\mathrm{pH} \mathrm{KCl} \mathrm{/} \mathrm{HCl}$ buffer of $\mathrm{pH}$ (2.2), Tris buffer $\mathrm{HCl}$ of $\mathrm{pH}$ (3.8), Tris buffer $\mathrm{HCl}$ of $\mathrm{pH}(6.3), \mathrm{Na}_{2} \mathrm{HPO}_{4} / \mathrm{NaH}_{2} \mathrm{PO}_{4}$ buffer of $\mathrm{pH}$ (9.2), and glycine / $\mathrm{NaCl}$ buffer of $\mathrm{pH}(12.6)$.In brief , $(50 \mu \mathrm{l})$ of $\mathrm{hGH}(10 \mathrm{mIU} / \mathrm{L})$ were completed to $(3 \mathrm{ml})$ with each of the previous buffers and scanned in the range $(200-350 \mathrm{~nm})$.

\section{2 - Effect of Different Halides:}

Different halides effect were examined on hGH spectrum. In brief, $(50 \mu \mathrm{l})$ of hGH $(10 \mathrm{mIU} / \mathrm{L})$ were completed to (3ml) with phosphate buffer of $\mathrm{pH}(7.4)$ containing $(0.01 \mathrm{M})$ of $\mathrm{NaF}$ and scanned in the range (200$350)$. The experiment was repeated by using phosphate buffer of $\mathrm{pH}(7.4)$ containing $(0.01 \mathrm{M})$ of different halides which were $\mathrm{NaCl}, \mathrm{NaBr}$, and $\mathrm{NaI}$ respectively.

\section{3 - Effect of Divalent Cations:}

Effect of different divalent salts on hGH spectrum was examined . In brief Fifty $(50 \mu \mathrm{l})$ of hGH $(10 \mathrm{mIU} / \mathrm{L})$ were completed to $(3 \mathrm{ml})$ with phosphate buffer of $\mathrm{pH}(7.4)$ containing $(25 \mathrm{mM})$ of $\mathrm{CaCl}_{2} \cdot 2 \mathrm{H}_{2} \mathrm{O}$. scanned in the range (200-350). The experiment was repeated by using phosphate buffer of $\mathrm{pH}$ (7.4) containing different divalent cations which were $\mathrm{MgCl}_{2} \cdot 6 \mathrm{H}_{2} \mathrm{O}, \mathrm{ZnSO}_{4} .7 \mathrm{H}_{2} \mathrm{O}$, and $\mathrm{CuSO}_{4} \cdot 5 \mathrm{H}_{2} \mathrm{O}$ respectively. 


\section{4- Effect of 8M Urea, $0.03 \mathrm{M}$ KCl on the hGH UV. spectrum:}

Fifty $(50 \mu \mathrm{l})$ of $\mathrm{hGH}(10 \mathrm{mIU} / \mathrm{L})$ were completed to $(3 \mathrm{ml})$ with phosphate buffer of $\mathrm{pH}(7.4)$ in the presence of (8M) Urea and scanned I the range (200-350). The The experiment was repeated in the presence of $(0.03 \mathrm{M}) \mathrm{KCl}$, and mixture (50:50) of $(8 \mathrm{M})$ Urea and $(0.03 \mathrm{M}) \mathrm{KCl}$.

\section{5- Observation of the Helix-Coil Transition of hGH Denaturation:}

Denaturation of hGH due to the effect of increasing temperature was studied. Fifty $(50 \mu \mathrm{l})$ of hGH $(10 \mathrm{mIU} / \mathrm{L})$ were completed to $(3 \mathrm{ml})$ with $20 \%$ ethyleneglycol buffer containing $(0.01 \mathrm{M}) \mathrm{NaCl}$. The solution was placed in $1 \mathrm{~cm}$ cuvette in the sample beam and the buffer at the adjusted $\mathrm{pH}$ in the reference beam. The absorption was measured at the wavelength of (292 and $295 \mathrm{~nm})$ at different temperature $\left(30,40,50,60,70 \mathrm{c}^{\circ}\right)$. The experiment was repeated by using $20 \%$ ethylene glycol buffer containing $(0.1 \mathrm{M}) \mathrm{NaCl}$

\subsection{UV. Spectrum of hGH macromolecule}

\section{Results and Discussion}

The UV. Spectrum of hGH was measured at $\mathrm{pH}(7.4)$ in spectrum region $(200-350 \mathrm{~nm})$ to determine the maximum wavelength $(\lambda \max )$. hGH UV. spectrum is illustrated in figure (1), as shown in this figure the hormone spectrum consists of two maximum wavelengths, $\lambda \max _{1}$ at $280 \mathrm{~nm}$ and $\lambda \max _{2}$ at $210 \mathrm{~nm}$ with absorbance of 0.030 and 0.390 respectively. The absorption at $280 \mathrm{~nm}$ is characteristic of tryptophyl residues while absorption at $210 \mathrm{~nm}$ is due to tyrosyl residues ${ }^{(3)}$ or histidyl residue.

Ultraviolet absorption spectrum of protein solutions in the region $(200-310 \mathrm{~nm})$ are contributed mainly from tryptophyl, tyrosyl, phenylalanyl, histidyl residues and the peptide bound ${ }^{(152)}$

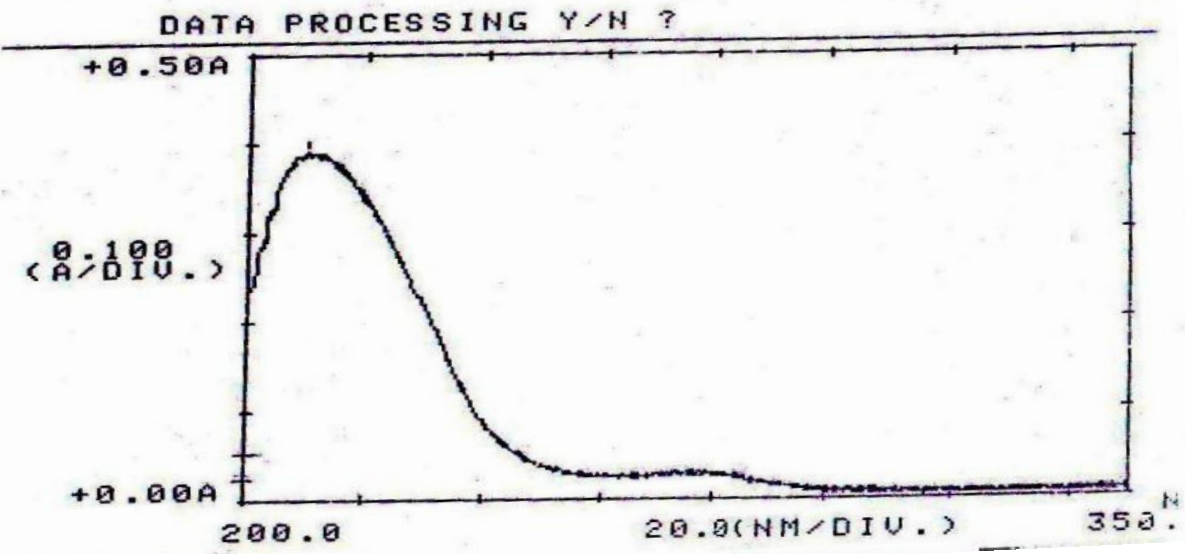

Fig (1) The UV. Spectrum of hGH in buffer of pH (7.4)

\subsubsection{Factors affecting the absorption properties of hGH macromolecule:}

The absorption spectrum of chromophores (unsaturated groups like aromatic amino acids) are determined by the chemical structure of the molecule. Changes in the environment of these chromophores can lead to alterations in the absorption spectrum, these changes (e.g. $\mathrm{pH}$, temperature, etc.) can affect the absorption spectrum if the interaction between the chromophore and the perturbing agent affects on the ground and excited states of the group which is responsible for absorption.

The altered spectrum can be shifted to a longer wave length (this is called red shift) or to a shorter wave length (which is called blue shift). The shift may or may not be accompanied by a change in intensity of the spectrum, although in many cases, a change in intensity of the spectrum occurs simultaneously with wave length shift $^{(4)}$.

\section{1 - pH Effects:}

The solvents $\mathrm{pH}$ determines the ionization state of ionisable chromophores ${ }^{(3)}$. The UV.spectrum of hGH was determined at five different $\mathrm{pH}(2.2,3.8,6.3,9.2,12.6)$. As shown in table (3.9) in the acidic region there is no shifting in $\lambda \max _{1}$ whereas $\lambda \max _{2}$ shifts to a shorter wavelengths (blue shift) at $(209.6,209.2,205.0$ $\mathrm{nm})$ with an absorbance of $(0.298,1.498,1.118$ respectively). This blue shift is due to the protonation, because when non bonding electrons (n) of oxygen atom in the carboxylic group of tyrosyl residues bond with a proton $\left(\mathrm{H}^{+}\right)$the energy level of these non bonding electrons decreases, therefore it needs more energy (blue shift) ${ }^{(5)}$. As 
shown in table (3.9) the blue shift increases with $\mathrm{pH}$ decrement because of increasing protonation of carboxylic group according to the following order: $6.3<3.8<2.2$. The intensity of absorption increases because tyrosyl residues localized on the outer surface of hormone which increases the probability of interaction between the radiation energy and the electronic system of tyrosyl residues ${ }^{(6)}$. When the $\mathrm{pH}$ increases to $(9.2,12.6)$ there is a significantblue shift in $\lambda \max _{1}(277.2,271.6 \mathrm{~nm}$ respectively) this could be due to the deprotonation effect of the solution.

ontryptophyl and it became buried inside the hormone structure so it needs more energy (blue shift) whereas $\lambda \max _{2}$ has a significant red shift to $(212.0,215.4 \mathrm{~nm}$ respectively) with an increment in absorption intensity $(1.319,1.484$ respectively). This red shift is due to deprotonation which makes tyrosyl residues more exposes to solvent so it needs lower energy (red shift) and increases the absorption intensity because the probability of interaction between the radiation energy and the electronic system increases. $\lambda \max _{2}$ red shift increases in the following $\mathrm{pH}$ order: $12.6>9.2$ because of deprotonation increment ${ }^{(3,6)}$.

\section{2 - Effects of Different Halids:}

The effects of $(0.01 \mathrm{M})$ of different sodium halids on hGH spectrum were examined.

As shown in table (3.12) for $\lambda \max _{1}$ (for tryptophyl residues) there was an increment in the blue shift while the intensity decreased, on the other hand there was an increment in the red shift for $\lambda \max _{2}$ (for tyroyl residues) with a decrement in the absorption intensity in the salt solution according to the following order:

\section{$\mathrm{Nal}>\mathrm{NaBr}>\mathrm{NaCl}>\mathrm{Naf}$}

\section{Increment in $\lambda \max _{1}$ blue shift \\ Increment in $\lambda \max _{2}$ red shift}

Decrement in absorption intensity for both $\lambda \max 1, \lambda \max 2$

Table (2) pH effects on UV. spectrum of hGH

\begin{tabular}{|c|c|c|c|c|}
\hline $\mathrm{pH}$ & $\lambda \max _{1}$ & $\lambda \max _{2}(\mathrm{~nm})$ & $\mathrm{Abs}_{1}$ & $\mathbf{A b s}_{2}$ \\
\hline 2.2 & 280 & 205.0 & 0.060 & 1.118 \\
\hline 3.8 & 280 & 209.2 & 0.150 & 1.498 \\
\hline 6.3 & 280 & 209.6 & 0.035 & 0.298 \\
\hline 7.4 & 280 & 210.0 & 0.030 & 0.390 \\
\hline 9.2 & 277.2 & 212.0 & 0.036 & 1.319 \\
\hline 12.6 & 271.6 & 215.4 & 0.048 & 1.484 \\
\hline
\end{tabular}

The blue shift in $\lambda \max _{1}$ occurs because the diffusion of double layer of charged particales (like salts) will tend to shield the charged species that is localized on the hormones surface, therefore $n \quad \Pi^{*}$ sition in tryptophyl residues need more energy to occur (blue shift). This blue shift increases according to previous order because of ionic radius of halid ions increase as in the following order: $\mathrm{I}^{>}>\mathrm{Br}^{-}>\mathrm{Cl}^{-}>\mathrm{F}^{-}$,so when ionic radius increases the shield of charged species increases which makes them need more energy (increment in blue shift), and the absorption intensity decreases because the interaction between radiation energy and electron system decreases because of the ionic

The red shift in $\lambda \max _{2}$ occurs because in aqueous solutions containing added salts the polarity increases which makes the polar groups (tyrosyl residues) become on the hormone surface and in contact with polar solvent so the energy level of $\Pi^{*}$ orbital decreases therefore $\Pi \longrightarrow \Pi^{*}$ transition in tyrosine needs lower energy (red shift). This red shift increases when polarity increases according to the previous order. Also red shift increment associated with absorption intensity decrement because of ionic radius increment ${ }^{(6,7)}$.

These results revealed that the tryptophyl residues were buried inside the hormone molecule while tyrosyl residues were on the surface.

Table (3) Effects of Halides on hGH UV. Spectrum.

\begin{tabular}{|l|lc|cc|}
\hline salts & $\lambda \mathbf{m a x}_{\mathbf{1}}$ & $\boldsymbol{\lambda \mathbf { m a x } _ { \mathbf { 2 } }}$ & $\mathbf{A b s}_{\mathbf{1}}$ & $\mathbf{A b s}_{\mathbf{2}}$ \\
\hline $\mathbf{h G H}$ in buffer of & 280.0 & 210.0 & 0.953 & 1.984 \\
$\mathbf{p H}(\mathbf{7 . 4 )}$ & & & & \\
\hline $\mathbf{N a F}$ & 278.2 & 229.8 & 0.912 & 1.824 \\
$\mathbf{N a c l}$ & 277.8 & 231.4 & 0.884 & 1.681 \\
$\mathbf{N a B r}$ & 276.4 & 239.8 & 0.822 & 0.698 \\
$\mathbf{N a I}$ & 275.6 & 241.4 & 0.920 & 0.685 \\
\hline
\end{tabular}




\section{3 - Effects of Divalent Cations:}

Several divalent cations had been used to study their action on hGH spectrum, these cations include $\mathrm{Ca}^{+2}$, $\mathrm{Mg}^{+2}, \mathrm{Zn}^{+2}$ and $\mathrm{Cu}^{+2}$ in a concentration of $(25 \mathrm{mM})$. hGH spectrums are shown in figures $(3.43-3.46)$. As shown in table (3.13) there were a blue shift and absorbance decrement in $\lambda \max _{1}$ for tryptophenyl residues (except in $\mathrm{CuSO}_{4}$ there is a significant red shift) whereas $\lambda \max _{2}$ for tyrosyl residues shifts to a longer wave length (red shift) (exception $\mathrm{CuSO}_{4} \lambda \max _{2}$ disappears). The red and blue shifts with their absorbance decreases in divalent salts solutions according to the following order: $\mathrm{CaCl}_{2}>\mathrm{Mg} \mathrm{Cl}_{2}>\mathrm{ZnSO}_{4}$. The blue shift of $\lambda \max _{1}$ is due to hydration and little destabilization of a few weak interactions of hGH which makes tryptophenyl residues buried more inside the hormone (in the non polar region) because of hydrophopic effects of solution which forcing them inside therefore it needs more energy (blue shift) and the absorbance decreases because of the same effect. The hydration and destabilization of $\mathrm{hGH}$ which causes this $\lambda \max _{1}$ blue shift increases according to the previous order because these two effects are higher in $\mathrm{CaCl}_{2}$ than in $\mathrm{MgCl}_{2}$ than in $\mathrm{ZnSO}_{4}{ }^{(8,9)}$. The shifts of $\lambda \max _{1}$ to a longer wavelength (red shift) in $\mathrm{CuSO}_{4}$ solution is due to denaturation of hGH because $\mathrm{Cu}^{+2}$ ions form a coordination complex with the nitrogen atoms of four peptide bonds, see figure $(3.47)^{(10)}$, therefore the tryptophenyl residues appear on the hormone surface which make them expose to solvent and need much lower energy (red shift) and absorbance increment whereas $\lambda \max _{2}$ disappears in $\mathrm{CuSO}_{4}$ also because of changing in the tertiary structure of hGH which makes tyrosyl residues buried inside the hormone and do not expose to solvents therefore $\lambda \max _{2}$ disappears ${ }^{(10)}$.<smiles>CN(C(N)=O)C(N)=O</smiles>

Figure (1) $\mathrm{Cu}^{+2}-$ protein Complex.

The significant red shift in $\lambda \max _{2}$ is due to hydration which makes tyrosyl residues more expose to solvents therefore $\lambda \max _{2}$ shifts to a longer wavelength (red shift) this red shift and the absorbance decreases when hydration decreases according to the previous order ${ }^{(11)}$.

Table (4) Effects of Divalent Cations on hGH UV. Spectrum.

\begin{tabular}{|l|lc|lc|}
\hline salts & $\lambda \mathbf{m a x}_{\mathbf{1}}$ & $\lambda \mathbf{m a x}_{\mathbf{2}}$ & $\mathbf{A b s}_{\mathbf{1}}$ & $\mathbf{A b s}_{\mathbf{2}}$ \\
\hline $\begin{array}{l}\mathbf{h G H} \text { in buffer } \\
\text { of } \mathbf{~ p H ~ ( 7 . 4 )}\end{array}$ & 280.0 & 210.0 & 0.030 & 0.390 \\
\hline $\mathbf{C a C l}_{2}$ & 277.0 & 230.8 & 1.157 & 1.884 \\
$\mathbf{M g C l}_{\mathbf{2}}$ & 277.8 & 230.2 & 1.036 & 1.867 \\
$\mathbf{Z n S O}_{2}$ & 278.0 & 230.0 & 0.888 & 1.794 \\
$\mathbf{C u S O}_{4}$ & 310.4 & & 2.596 & \\
\hline
\end{tabular}

\section{4- Effects of Urea and $\mathrm{KCl}$ :}

The effects of urea $8 \mathrm{M}$ and KCL $0.03 \mathrm{M}$ and a mix of (50:50) of urea $8 \mathrm{M}$ and $\mathrm{KCl} 0.03 \mathrm{M}$ at pH (7.4) on hGH spectrum were examined in this experiment. Figures $(3.48-3.50)$ show hGH spectrums. As shown in table (3.14) in urea there is a blue shift in $\lambda \max _{1}$ for tryptophyl residues to $(276.2 \mathrm{~nm})$ because urea is 
a chaotropic agent that causes hGH denaturation by solvating the non polar groups in the interior of the hormone. The urea molecules disrupt the hydrophobic interactions that normally stabilize the native conformation and form a random coil. In this denature conformation the tryptophyl were more buried inside hGH therefore it needs more energy (blue shift) whereas $\lambda \max _{2}$ for tyrosyl residues shifts to a longer wavelength (red shift) because tyrosyl residues become on the outer surface of hormone and more expose to solvents therefore it needs lower energy (red shift), this red shift accompanied by increment in absorption intensity as compared to $\lambda \max _{2}$ absorbance in phosphate buffer of $\mathrm{pH}=7.4$, this increment is due to increase interaction between radiation energy and electron system of tyrosyl residues because they localized on the outer surface of $\mathrm{hGH}^{(5,6)}$. In $\mathrm{KCl}$ solution as shown in table (3.14) there was an increment in blue shift for $\lambda \max _{1}$ to $(275.2 \mathrm{~nm})$ as compared to that in urea, because there was no conformational change in hGH structure in $\mathrm{KCl}$ solution but the blue shift in $\lambda \max _{1}$ was due to hydrophobic effect of solution which buried the non polar groups (tryptophenyl residues) inside the hormone so they need higher energy (blue shift) whereas the polar groups (tyrosyl residues) become more reveal on the outer surface and surround by positive $\left(\mathrm{K}^{+}\right)$or negative $\left(\mathrm{Cl}^{-}\right)$ charges near the amide group of the chromophore (tyrosyl residues) which might interact with $\Pi$ electron system of amide group, this interaction increases the stability of $\Pi^{*}$ electrons therefore it needs so lower energy and this causes a significant red shift in $\lambda \max _{2}$ to $(243.0 \mathrm{~nm})$ accompanied by absorbance increment as compared to that in phosphate buffer $(\mathrm{pH}=7.4)^{(7,12)}$.

In the mixed solution of urea and $\mathrm{KCl}(50: 50)$ there was a blue shift in $\lambda \max _{1}$ to $(277.6 \mathrm{~nm})$ with absorbance increment and red shift in $\lambda \max _{2}$ to $(239.0 \mathrm{~nm})$ with absorbance increment. The blue shift and red shift were due to changes in tertiary structure of the hormone because of hydrophobic effect which was buried the tryptophyl residues so the blue shift in $\lambda \max _{1}$ occurs and revealed the tyrosyl residues so the red shift in $\lambda \max _{2}$ occurs accompanied by significant absorbance increment $(2.211)^{(5,6)}$.

The results of this experiment show that changes in absorption near $230 \mathrm{~nm}$ were larger than those near $280 \mathrm{~nm}$. This agreed with Glazer (1978) who noted that solvent perturbation or denaturation of protein produces much larger changes in absorption near $230 \mathrm{~nm}$ than $280 \mathrm{~nm}$. Some of these changes in absorption may be produced by changes in $n \quad \Pi^{*}$ absorption or because of changing in the protein geometrical arrangement or because of environmental changes ${ }^{(12)}$.

\section{5 - Effect of different temperature on helix - coil transition of hGH:}

The effect of different concentrations of $\mathrm{NaCl}$ on thermal stability of hGH macromolecule was examined in this experiment. The value of absorbance (A) at $\lambda$ max $(292,295 \mathrm{~nm})$ for tryptophyl and tyrosyl residues respectively in $\mathrm{NaCl}(0.1 \mathrm{M}$ and $0.01 \mathrm{M})$ in $20 \%$ ethylenglycol buffer at different temperatures $(30,40$, $\left.50,60,70 \mathrm{c}^{\circ}\right)$ are shown in figures $(3.51,3.52)$.

As shown in these figures the absorbance of both tryptophyl $\quad(\lambda \max =292 \mathrm{~nm})$ and tyrosyl $(\lambda \max =$ $295 \mathrm{~nm}$ ) increase with temperature increment for both concentrations of $\mathrm{NaCl}$ reaching the highest absorbance at $70 c^{\circ}$. The high temperature disrupts the chemical links that hold hormones three - dimensional shape this causes unfolding of hGH and loss of its shape ${ }^{(13)}$. In this unfolding shape the buried chromophores in the native hGH become exposed to the solvent which leads to increment in the absorbance of both tryptophyl and tyrosyl residues at $70 \mathrm{c}^{\circ}$ in both concentrations ${ }^{(14)}$. The decrement in absorbance occurs because the unfold hormone will refold in $\mathrm{NaCl} /$ Ethylen glycol buffer and then unfold again till the hydrogen bonds that responsible for holding the helical conformation of hGH degrade and hGH becomes insoluble at more than $80 \mathrm{c}^{\circ}{ }^{(15,16,17)}$. As shown in figures $(3.51,3.52)$ the absorbance in. $0.1 \mathrm{M} \mathrm{NaCl}$ is lower than in $0.01 \mathrm{M}$ of $\mathrm{NaCl}$ this could due to the shielding effect of $\mathrm{NaCl}$ which may causes this decrement ${ }^{(18)}$.

Figure (3.51) Different temperature effects on: hGH absorbance at $(292,295 \mathrm{~nm})$ in $0.01 \mathrm{M} \mathrm{NaCl}$.

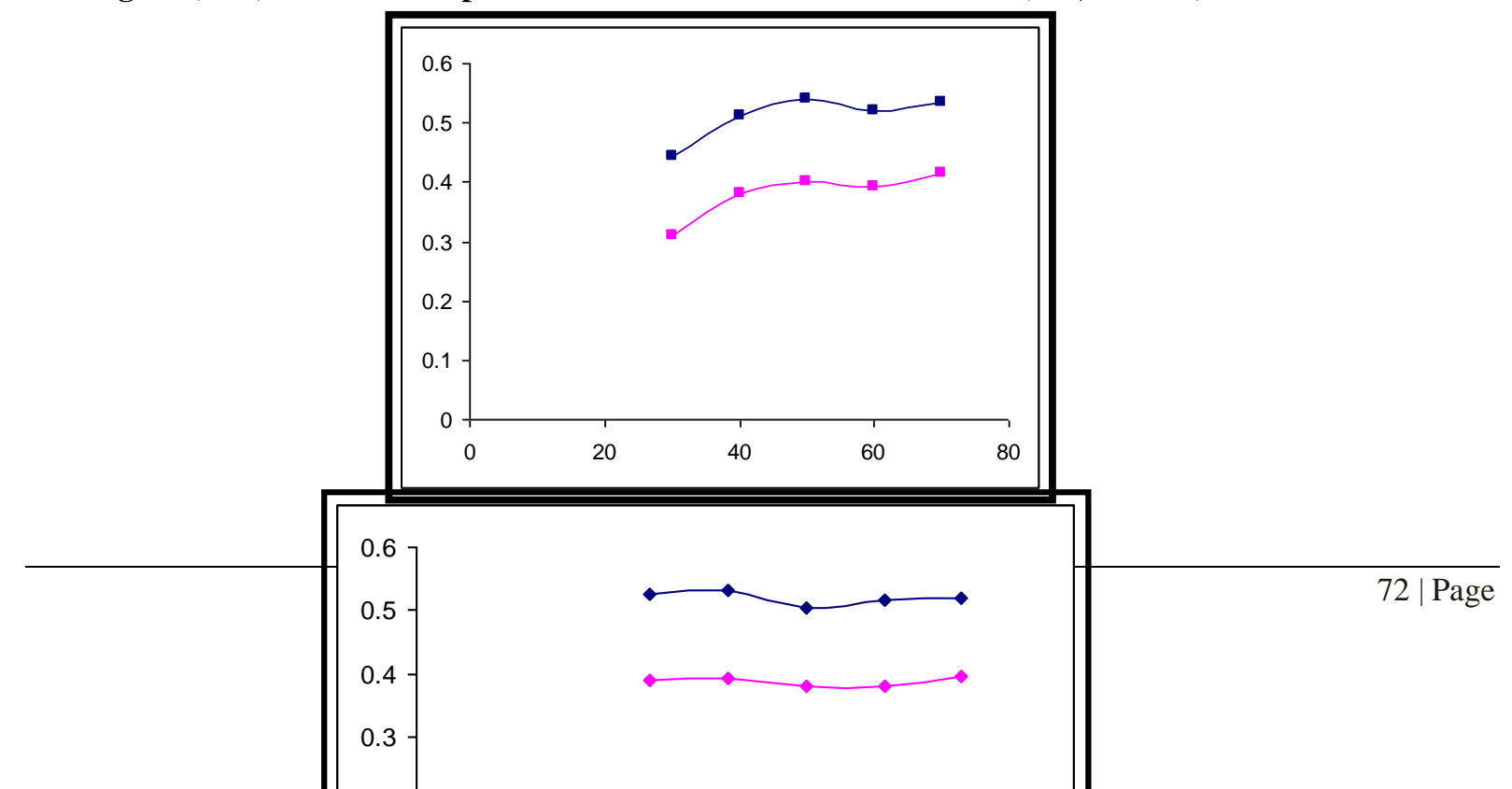


Figure (3.52) Different temperature effects on: hGH absorbance at (292, $295 \mathrm{~nm})$ in $0.1 \mathrm{M} \mathrm{NaCl}$.

\section{Conclusions}

The UV. studies on hGH macromolecules revealed that the hormone affected by chemical reagents which changed its conformation and folding. These studies helped in discovering what could happen to GH molecule when the biochemistry of body changed because of diabetes. The results revealed that tryptophyl residues were inside the hormone and tyrosyl residues were on the surface.

\section{References}

[1]. Murray, K.R.; Granner, K. D. and Mayes, A. P., (2000): Pituitary and Hypothalamic Hormones. In: Harper's Biochemistry. 25 ${ }^{\text {th }}$ ed.., Appleton and Lange, Stamford, Chap.45, pp: $552-554$

[2]. Mader, S.S. and Galliart, L. P. (2001): The Endocrine system. In : Understanding Human Anatomy \& physiology. 4th ed. McGraw - Hill Companies, Inc., Chap.10, p: 187.

[3]. Freifelder, D. (1984): Physical Biochemistry and Its Application in Biochemistry and Molecular Biology. BrandessUniversity, Chap.14, pp: $391-420$.

[4]. Donavan, J. W. (1973): "Ultraviolet Difference Spectroscopy: New Techiques and Applications" In: Methods in Enzymology, Academic press, C. H. W Hirs and S. N. Timasheff, p: $497-548$

[5]. Horton, R. H.; Moran, A. L. and ochs, S. R. (2002): Principles of Biochemistry, 3ed ed., Prentice - Hall, Inc., (USA), Chap.4, pp: $114-121,104-105$.

[6]. Silverstein, M. R.; Basser, C. G. and Morrill, C. T. (1981): Spectrometric Identification of Organic Compounds., $4^{\text {th }}$ ed., John Wiley \& sons, Inc., (USA), Chap.6, pp: $305-323$.

[7]. Alhaidary, A. A. (1992): Instrmental Methods of Chemical Analysis, Alhikma House, Baghdad, Chap.5, pp: 145 - 162.

[8]. Arakawa, T.; Bhat. R. and Timasheff, S. N. (1990): "preferential interactions determine protein solubility in three- component solutions: the $\mathrm{MgCl}_{2}$ system" Biochemistry; 29 (7): 1914 - 23.

[9]. Arakawa, T.; and Timasheff, S. N. (1984): "Mechanism of protein salting in and salting out by divalent cation salts: balance between hydration and salt binding" Biochemistry; 23 (25): $5912-23$.

[10]. Buckberry, D. L. and Teesdale, H. P. (2001): Essentials of Biological chemistry., John Wiley \& Sons, Ltd., New York, Chap.4, pp: $94-95$.

[11]. Arakawa, T.; Bhat, R. and Timasheff, S. N. (1990): “ Why preferential hydration dose not always stabilize the native structure of globular proteins". Biochemistry; 29 (7): $1924-31$.

[12]. Van wart, H. E. and scheraga, H. A. (1978): "Raman and Resonance Raman spectroscopy" In: Methods in Enzymology, Academic press, C. H. W. Hirs and S. N. Timasheff, vol. 49, pp: $67-148$.

[13]. .Insel, P.; Turner, E. R. and Ross, D. (2003): Discovering nutrition., Jones and Bartlett Publishers, Inc., (USA), Chap.7, pp: 199 200 .

[14]. Schulz, G. E. and schirmer, R. H. (1990): "Principles of protein structure", In: Springer Advanced Texts in chemistry, (Ed. C. R. Cantor), springer - Verlag, New York, pp: $1-32$

[15]. Atkins, P.; Jones, L. and Tasker, R. (2002): chemical principles The Quest for Insight, $2^{\text {nd }}$ ed., W. H. Freeman and company, New York, Chap.19, pp: $1013-1014$

[16]. Murray, K. R.; Granner, K. D. and Rodwell, W. V. (2006): Proteins: Higher orders of structure. In: Harper's Illustrated. Biochemistry. $27^{\text {th }}$ ed., McGraw - Hill companies, Inc., Asia, chap. 5, pp: $30-39$.

[17]. Sheu, I. J. and sheu, Y. E. (2006): "Characterization, of DNA Degradation using Direct current conductivity and Dynamic Dielectric Relaxation Techniques", AAps pharm. Sci. Tech., 7 (2), Article 36, p: $E_{1}-E_{7}$

[18]. Christopher K. Mathews and K. E. van Holde (1991) "Biochemistry" isted, The Benjamin / Cummings Publishing Company. Inc. California, Chap.2, p: 30 